\title{
Hypertrophic pulmonary osteoarthropathy complicating Celestin tube insertion
}

\author{
J. B. YOUNG \\ M.B., M.R.C.P.
}

\author{
W. E. WILKINS \\ M.B., M.R.C.P.
}

Leeds General Infirmary, Great George Street, Leeds LS1 3EX and Royal United Hospital, Combe Park, Bath, Avon

\begin{abstract}
Summary
A case is reported in which hypertrophic pulmonary osteoarthropathy (HPOA) developed following the insertion of a Celestin tube for a benign oesophageal stricture. The HPOA resolved completely following removal of the tube. It is believed that the Celestin tube was the major factor causing the HPOA, a complication of Celestin tube insertion not previously reported.
\end{abstract}

KEY WORDS: oesophagitis, hypertension, osteomyelitis.

\section{Introduction}

The technique of peroral oesophageal intubation aided by the flexible fibreoptic endoscope represents a considerable advance in the management of stenosing oesophageal lesions. Increased use of the method has been accompanied by reports on complications (Ranson and John, 1979; Shaw and Combes, 1979; Brown and Hughes, 1979). We report a case in which hypertrophic pulmonary osteoarthropathy (HPOA) developed following oesophageal intubation.

\section{Case report}

A 57-year-old metallurgist presented in 1977 with dysphagia and a 2-year history of symptoms suggesting gastro-oesophageal reflux. He was a non-smoker and at this time there were no respiratory symptoms. In 1951 a right mid-thigh amputation had been performed for osteomyelitis, and from 1971 he had been treated for hypertension with methyldopa.

Clinical examination and a chest X-ray were normal, but an upper gastrointestinal endoscopy demonstrated a hiatus hernia with a tight stricture at the gastro-oesophageal junction, and severe oesophagitis extending $8 \mathrm{~cm}$ proximally. A Boerema surgical repair was carried out and, as was surgical practice at the time, a Celestin tube inserted: the tube was inserted with the aim of avoiding early restrictur- ing and was intended to be left in situ for 3-4 months.

Three months later he was readmitted with a productive cough persisting in spite of antibiotic treatment, and painful, swollen wrists and ankle. On examination he had respiratory crackles over the left lower posterior thorax, and hot, tender, swollen wrists and right ankle with clubbing of fingers and $c$ toes. Chest X-ray showed patchy shadowing in the $\stackrel{\ulcorner}{\gtrless}$ left lower lobe, and $X$-rays of affected joints showed extensive periosteal new bone formation (Fig. 1). A clinical diagnosis of bronchial carcinoma complicated by HPOA was made. A bronchoscopy with biopsies was performed which showed only inflammatory changes in the left lower lobe bronchus and no evidence of malignancy. Failure to confirm the diagnosis led to other investigations, including an upper gastrointestinal endoscopy which showed extensive severe oesophagitis now extending $15 \mathrm{~cm}$ above the gastro-oesophageal junction. It was assumed that the oesophagitis and possibly pulmonary symptoms were due to increased reflux through the Celestin tube, which was therefore removed.

Following this, his respiratory symptoms improved and within 2 months the joint swelling and pain disappeared. Repeat endoscopic examination showed resolution of the oesophagitis, and a barium meal showed no evidence of reflux. Further joint X-rays demonstrated complete resorption of the periosteal new bone, and he has subsequently remained well.

\section{Discussion}

The cause of HPOA is unknown. It occurs most commonly as a secondary manifestation of pulmonary disorder, e.g. bronchial malignancy and bron- 0 chiectasis. Improvement in symptoms can occur with $\mathbb{D}$ the administration of steroids or adrenergic blockade ? but resolution of the radiographic changes occurs only after successful treatment of the underlying disorder or a vagotomy (Ginsberg, 1963; Leading Article, 1977). 

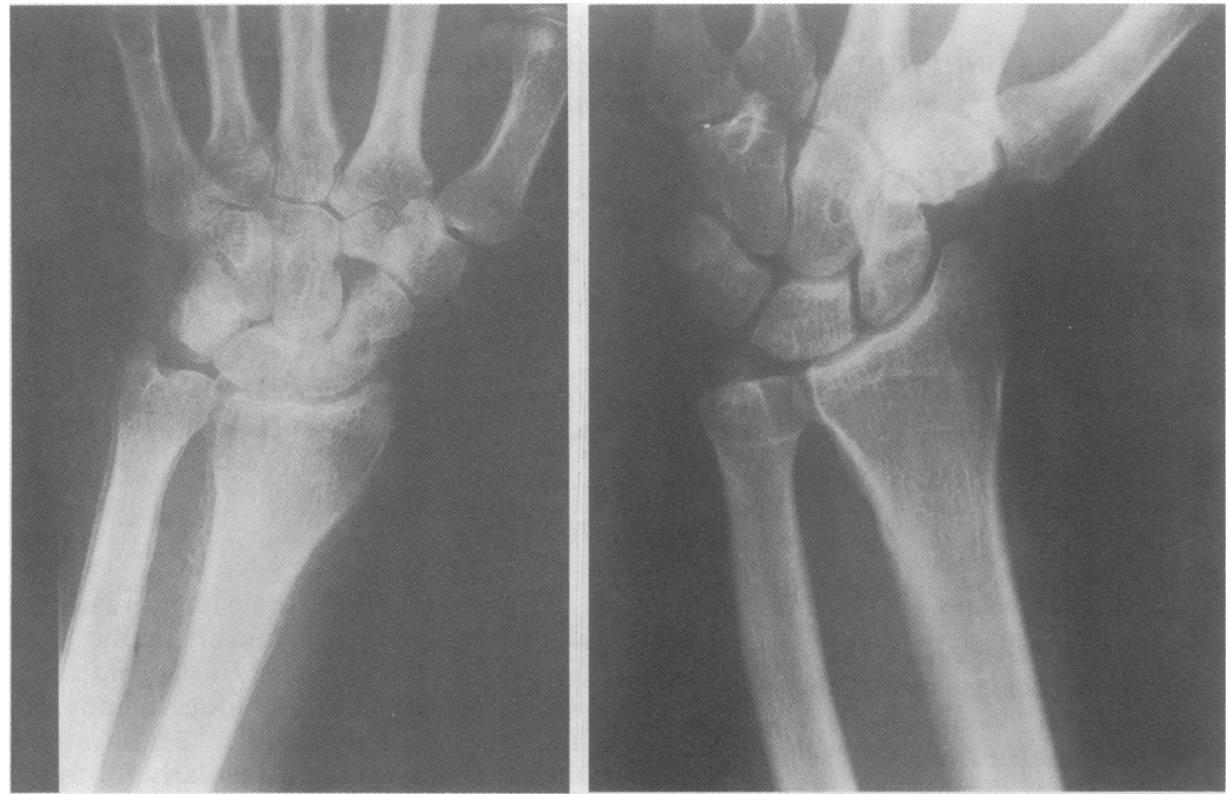

FIG. 1. Wrist X-ray before (left) and after (right) removal of Celestin tube showing resolution of the periostitis.

In the case we have described, removal of the Celestin tube resulted in complete resolution of clinical and radiographic signs of HPOA. However, concern about an underlying bronchial carcinoma remained for a number of months. It is now 5 years since his clinical presentation, and it would seem reasonable, therefore, to implicate oesophageal intubation and tracheo-bronchial aspiration as the major factor in the development of the HPOA. This complication has not previously been reported in association with oesophageal intubation.

\section{References}

BRown, P. \& HUGHES, R.G. (1979) Late complications of endoscopic oesophageal tube insertion. British Medical Journal, 2, 970. GINSBERG, J. (1963) Hypertrophic pulmonary osteoarthropathy. Postgraduate Medical Journal, 39, 639.

LEADING ARTICLE (1977) Finger clubbing and hypertrophic pulmonary osteoarthropathy. British Medical Journal, 2, 785.

RANSON, M.B. \& JOHN, H.T. (1979) Complications associated with the use of the Celestin tube for benign oesophageal obstruction. British Journal of Surgery, 66, 110.

SHAW, J.H.L. \& COMBES, G.B. (1979) Multiple intestinal perforation due to celestin tube. British Journal of Surgery, 66, 807.

(Accepted 24 May 1983). 